\title{
Regulation of Mannitol Dehydrogenase: Relationship to Plant Growth and Stress Tolerance
}

\author{
D.M. Pharr' ${ }^{1}$, R.T.N. Prata ${ }^{2}$, D.B. Jennings ${ }^{2}$, J.D. Williamson ${ }^{3}$, and E. Zamski ${ }^{4}$ \\ Department of Horticultural Science, North Carolina State University, Raleigh, NC 27695-7609 \\ Y.T. Yamamoto ${ }^{5}$ and M.A. Conkling 6 \\ Department of Genetics, North Carolina State University, Raleigh, NC 27695-7614
}

Mannitol, a six-carbon alcohol, comprises up to $50 \%$ of the phloem-translocated photoassimilate in celery and closely related celeriac (knob celery) Apium graveolens L. var. dulce (Mill.) Pers. Many other species also form and translocate mannitol (see Stoop et al., 1996b, for review). Plants that form mannitol also form sucrose or, as in olive, the raffinose saccharides (Flora and Madore, 1993). Thus, mannitol comprises only a portion of the phloem-translocated carbo-

Received for publication 15 Oct. 1998. Accepted for publication 17 Nov. 1998. Sponsored in part by USDA/NRI Grant number 9702011 to D.M.P., J.D.W., and M.A.C. and by the North Carolina Agricultural Research Service (NCARS), Raleigh. Use of trade names in this publication does not imply endorsement by the NCARS of products named, nor criticism of similar ones not mentioned. The cost of publishing this paper was defrayed in part by the payment of page charges. Under postal regulations, this paper therefore must be hereby marked advertisement solely to indicate this fact.

${ }^{1}$ Professor.

${ }^{2}$ Graduate Student.

${ }^{3}$ Research Assistant Professor.

${ }^{4}$ Visiting Scientist. Permanent affiliation: Dept. of Agricultural Botany, The Hebrew Univ., Rehovot, Israel.

${ }^{5}$ Postdoctoral Researcher.

${ }^{6}$ Associate Professor. hydrate and does not completely supplant sugar translocation in these species.

Mannitol is not only an important phloem-translocated photoassimilate but is also a compatible solute that mediates protection against salt- and osmostress (Pharr et al., 1995) that can severely reduce agricultural productivity. Because mannitol may alleviate some of these stresses, considerable effort is being directed toward engineering plants that do not contain mannitol to produce it to exploit the beneficial effects of this hexitol on stress tolerance. However, plants currently engineered to produce mannitol may not as yet be agriculturally useful, as at least one report suggests that mannitolforming transgenic plants grow slowly (Karakas et al., 1997). The reason for this is not clear, but could indicate that these plants do not have a pathway for mannitol catabolism found in species that naturally form and utilize this compound.

These efforts to produce stress-tolerant plants through bioengineering precede detailed knowledge of how mannitol metabolism is regulated in plants such as celery, which normally produce and utilize mannitol. Such species serve as models from which to learn more about the control of mannitol biosynthesis and catabolism. This paper briefly reviews recent research concerning mannitol and stress tolerance in transgenic plants and the regulation of mannitol metabolism in celery. 


\section{MANNITOL AND STRESS TOLERANCE IN TRANSGENIC PLANTS}

Several studies have used the $m t l D$ gene encoding a bacterial mannitol-1-P dehydrogenase fused to the constitutively expressed cauliflower mosaic virus $35 \mathrm{~S}$ promoter to produce transgenic plants that accumulate mannitol (Karakas et al., 1997; Tarczynski et al., 1992, 1993; Thomas et al., 1995). These mannitol-accumulating transgenic tobacco and Arabidopsis plants, species in which neither mannitol or high salinity tolerance normally occur, exhibit increased tolerance to salinity (Tarczynski et al., 1993; Thomas et al., 1995). In characterizing salinity tolerance in a $+m t l D$ tobacco transformant line, Karakas et al. (1997) found that the transgenic plants grew slowly. The authors postulated that slower growth per se would result in slower ion uptake and thus greater salinity tolerance. In this view, mannitol would have no specific role in tolerance to salinity in these transgenic plants other than that associated with its apparent adverse effect on growth.

Despite the reservation arising from the work of Karakas et al. (1997), recent studies by Shen et al. (1997) provide interesting evidence for a specific mechanism by which mannitol can function as an osmoprotectant. In these studies, a chimeric $m t l D$ gene incorporating a pea chloroplastic transit sequence was used to target the $m t l D$ gene product to the chloroplasts of transgenic tobacco. The transgenic plants accumulated up to $100 \mathrm{~mm}$ mannitol, most of which was located within their chloroplasts, and exhibited normal photosynthetic rates and normal phenotype. Why these plants (Shen et al., 1997) were normal in phenotype, whereas those expressing the $m t l D$ gene without chloroplastic targeting of the gene product exhibited a slow growth phenotype (Karakas et al., 1997), is unknown. Nevertheless, the plants with chloroplastic mannitol exhibited several stress tolerances that could not be attributed to a slow growth phenotype. Leaf discs and isolated mesophyll cells of the transformed tobacco were more resistant to paraquat (1,1'-dimethyl-4,4' bipyridinium dichloride) than those from nontransformed plants, apparently due to the ability of mannitol to scavenge reactive oxygen species induced by the herbicide within the chloroplasts. While mannitol had previously been shown to quench enzyme-damaging hydroxyl radicals in vitro (Smirnoff and Cumbes, 1989), this was the first demonstration of the antioxidant function of mannitol in vivo. The precise mechanism by which mannitol scavenges oxygen radicals is not known.

Plants under drought and salinity stress may produce reactive oxygen species in excess of the levels that normal scavenging systems can accommodate (Smirnoff, 1993). Tobacco plants transformed with the $m t l D$ gene product targeted to chloroplasts exhibit increased tolerance to salinity (Hans J. Bohnert, personal communication), suggesting that one mechanism by which mannitol may function as an osmoproctectant is through its ability to scavenge reactive oxygen species.

\section{MANNITOL AND STRESS TOLERANCE IN PLANTS THAT FORM AND UTILIZE MANNITOL}

The antioxidant role of mannitol assumes increased importance in light of a recent study demonstrating that $20 \%$ to $38 \%$ of leaf mesophyll cell mannitol is located within the chloroplasts of parsley, Petroselinum crispum (Mill.) A.W. Hill, and snapdragon, Antirrhinum majus L. (Moore et al., 1997). These are two species that normally form mannitol photosynthetically. The concentration of mannitol within the chloroplasts of these species was estimated to be $\geq 100$ $\mathrm{mM}$ - the same concentration range providing stress protection in transgenic tobacco. Thus, species normally forming mannitol may be afforded the same benefits from chloroplastic mannitol as the transgenic tobacco discussed above. Sucrose, the other major photosynthetic product in both parsley and snapdragon, was not found in significant concentrations in chloroplasts. The presence of mannitol in chloroplasts of parsley and snapdragon implies the presence of mannitol translocation into the organelles, because as discussed later, the chloroplast is not the normal site of mannitol synthesis.

The above observations focus on stress-related metabolism in chloroplasts. Studies using suspension-cultured cells of celery demon- strated clearly that mannitol can protect nonphotosynthetic cells as well. Direct beneficial effects on stressed cells were demonstrated. For instance, when celery cells in suspension culture were grown on either sugar or mannitol as the sole carbon source and then stressed with $\mathrm{NaCl}$, the cells growing on mannitol were twice as tolerant as those growing on sugars (Pharr et. al., 1995). Cells growing on either carbon source increased their internal osmolality to the same extent by accumulating either sugars or mannitol as part of their osmoregulation response. Although the growth rate was reduced, cells grown on mannitol survived exposure to $300 \mathrm{~mm} \mathrm{NaCl}$, whereas those grown on sugars did not. The difference in response to $\mathrm{NaCl}$ cannot be attributed to inherent differences in growth rate, as the cells grow equally well on mannitol or sugars in the absence of $\mathrm{NaCl}$ (Stoop and Pharr, 1993). Further, these cells are nonphotosynthetic and are not green. Thus, the protective effect of mannitol is not at the level of the chloroplast. The observation that mannitol is more effective than sugars in alleviating salinity stress points to a role(s) for mannitol in stress protection that exceeds a function as a simple osmolyte adjusting water balance. The mechanism by which such stress protection is conferred is not fully understood, and the term 'osmoprotectant' has been proposed to differentiate the action of compounds such as mannitol from that of simple osmolytes with the exclusive role of osmotic adjustment (Le Rudulier et al., 1984).

\section{NORMAL LOCALIZATION AND FUNCTION OF ENZYMES OF MANNITOL BIOSYNTHESIS AND CATABOLISM}

The pathway of photosynthetic mannitol biosynthesis via the cytosolic enzyme mannose-6-P reductase (M6PR) was discovered in fully mature leaves of celery in the early 1980s and its occurrence has since been confirmed in other higher plants (Loescher et al., 1992; Rumpho et al., 1983). The enzyme is extra-plastidial, occurring almost exclusively in the cytosol of photosynthetic leaf cells of celery plants (Everard et al., 1993). Our laboratory discovered the pathway of mannitol catabolism in roots of celeriac [Apium graveolens L. var. rapaceum (Mill.) Gaud.] plants, and subsequently purified the initial enzyme of the pathway, mannitol dehydrogenase (MTD), from celery suspension cells growing on mannitol. Polyclonal antiserum was raised against the purified MTD in rabbits (Stoop et al., 1995), and a full length cDNA encoding the protein was cloned (Williamson et al., 1995). Strong predicted protein sequence homology between MTD and ELI3, a pathogenesis-related protein from Arabidopsis and parsley, was noted (Williamson et al., 1995). Additionally, MTD was induced in cell culture by salicylic acid, a known mediator of a number of plant defense responses. Mannitol oxidation by ELI3 proteins has yet to be conclusively demonstrated, but a role for MTD in disease defense response may be implied by these observations. A putative mechanism by which MTD might be involved in plant disease resistance involving reactive oxygen species has been hypothesized (Stoop et al., 1996b). Active oxygen species have been implicated in mediating a number of plant defense responses. For example, upon invasion by pathogens, plants produce a burst of active oxygen species apparently directed at limiting the growth of the pathogen (Durner et al., 1997). Pathogens, particularly fungi, produce mannitol that may function to override the oxidative plant defense response by quenching the active oxygen species (Stoop et al., 1996b). To counter this fungal defense, plants may produce mannitol dehydrogenase, resulting in conversion of mannitol to the non-quenching sugar mannose. This would allow the reactive oxygen species produced by the plant to damage the fungus, providing a successful defense response.

Celery MTD is a 1-oxidoreductase with substrate stereospecificity such that it will oxidize alditols with $2 R$ chirality adjacent to the terminal carbon undergoing oxidation (Stoop et al., 1996a). Stated otherwise, the structure of the alditol to be oxidized must have the same configuration about the carbon adjacent to the terminal carbonyl group as that in mannitol. The total number of carbons in the alditol chain and the configuration of hydroxyl groups at other carbons is a much less critical factor determining the suitability of a compound as a substrate for MTD. The physiologically important product of mannitol oxidation by MTD is mannose. However, this is not the only possible 
reaction catalyzed with physiologically important alditols. The stereospecificity of the enzyme is such that it also recognizes carbon 5 of sorbitol and galactitol, two other hexitols that occur in various plant species. Carbon 6 of these two hexitols is oxidized, resulting in the production of L-gulose and L-galactose, respectively. Apparently, neither of these sugars are metabolized further by plants. Hence, Mtd should be used with caution in genetic engineering, as introducing MTD into species containing hexitols other than mannitol might disrupt metabolism by producing dead-end oxidation products. This may not constitute a metabolic problem in nature, because plants containing MTD and mannitol rarely contain sorbitol or galactitol as well (Moore et al., 1997).

The MTD-catalyzed reaction is reversible, but the $\mathrm{Km}$ for mannose is quite high (Stoop et al., 1995), a fact that reinforces the idea that the physiologically important reaction is mannitol oxidation to mannose. Mannose is subsequently phosphorylated to mannose-6-P and isomerized to fructose-6-P, a sugar that can enter all central metabolic pathways of carbohydrate metabolism. The reactions leading from mannitol to fructose-6-P are shown below.

$$
\begin{aligned}
& \text { 1. mannitol }+\mathrm{NAD}^{+} \longrightarrow \text { mannose }+\mathrm{NADH}+\mathrm{H}^{+} \\
& \text {mannitol dehydrogenase } \\
& \text { (MTD) } \\
& \text { 2. mannose + ATP } \underset{\substack{\text { hexokinase } \\
(\text { HK) }}}{\longrightarrow} \text { mannose-6-P + ADP } \\
& \text { 3. mannose-6-P } \longrightarrow \text { fructose-6-P } \\
& \text { phosphomannose isomerase } \\
& \text { (PMI) }
\end{aligned}
$$

The enzymes HK and PMI were both found in all tissues of celery plants at high activity levels (Stoop and Pharr, 1994); PMI was present at particularly high activity $\left(30-50 \mu \mathrm{mol} \cdot \mathrm{h}^{-1} \cdot \mathrm{g}^{-1}\right.$ fresh weight) in celery plants. The MTD activity was much more restricted throughout celery plants than were HK and PMI activities; it was found in actively growing root tips, young expanding leaves, and small actively growing petioles, but its activity was lower or not detectable in mature parts of the plant, such as older roots, fully grown leaf petioles, and fully expanded leaves (Stoop and Pharr, 1992). Immunolocalization using anti-MTD serum showed that the MTD protein and MTD enzyme activity had very similar distributions in celery plants (Zamski et al., 1996). Unexpectedly, immunolocalization studies showed that MTD protein was also present in phloem tissues throughout the plant. Oxidation of mannitol during transport may provide energy for phloem loading and unloading, as has been postulated for sucrose and phloem-localized sucrose synthase (Nolte and Koch, 1993). In celeriac plants, MTD activity was inversely proportional to mannitol concentration in several plant organs (Stoop and Pharr, 1992). Based upon this inverse relationship, the amount and activity level of MTD protein in various parts of plants appears to determine their capacity to catabolize mannitol.

\section{CONTROL OF MTD ACTIVITY IN CELERY CELLS AND TISSUES REFLECTS REGULATION OF THE MTD GENE}

Several factors have been identified that influence MTD activity, as well as the abundance of MTD protein and Mtd transcripts (Stoop et al., 1996b). High salinity in the rhizosphere markedly reduced MTD activity in root tips and in all other young growing tissues of celery plants (Stoop and Pharr, 1994). This reduction was associated with increased mannitol accumulation throughout the plant, but not increased accumulation of sugars, implying a specific down-regulation of MTD and mannitol catabolism (Stoop and Pharr, 1994). Subsequently, using celery cell suspension cultures as a model system, Williamson et al. (1995) showed that excess salinity markedly reduced the abundance of Mtd RNA as well as MTD activity. This results in the retention and increased concentration of mannitol in salinity stressed plants while allowing continued sugar utilization. Conservation of the hexitol during stress is presumably very advantageous due to its osmoprotective role.

\section{SUGAR REPRESSION OF MTD REGULATES MANNITOL UTILIZATION IN CELERY}

Evidence from our laboratory suggests that repression of Mtd by sugar may be a major factor regulating mannitol utilization in celery. The carbon source upon which celery cells are grown influences the amount of MTD activity expressed by the cells (Prata et al., 1997; Stoop and Pharr, 1993). Cells grown on sugars contain less MTD activity, MTD protein, and $M t d$ RNA than do those grown on mannitol (Prata et al., 1997; Williamson et al., 1995). Immunolocalization of MTD in cells cultured on either sucrose or mannitol provides a striking illustration of the difference in MTD abundance (Fig. 1). Cells grown on mannitol showed intense reaction with anti-MTD serum, indicating a high titer of MTD protein (Fig. 1A), whereas those grown on sucrose showed little reaction (Fig. 1B). Cells grown on mannitol also showed

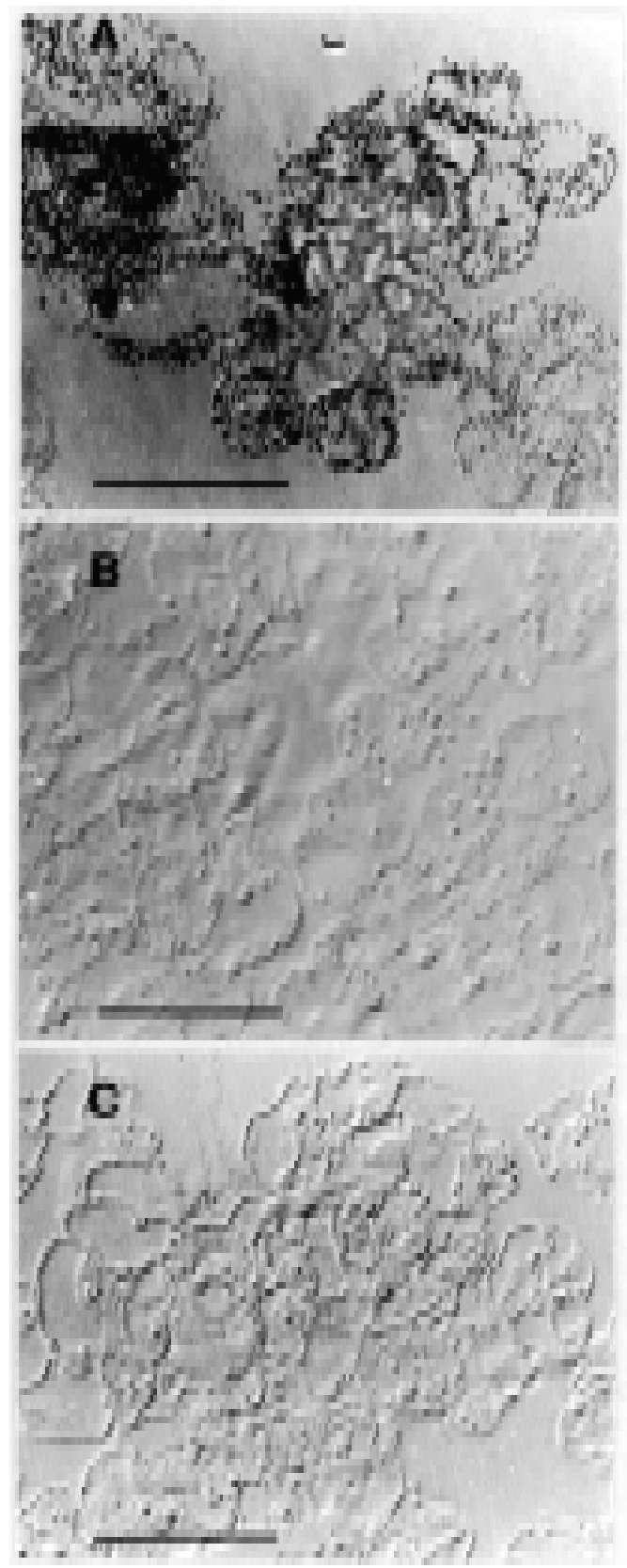

Fig. 1. Immunolocalization of MTD in 7-d-old celery suspension culture cells. Cells were fixed in glutaraldehyde, dehydrated in an ethanol series, embedded in London Resin White and sectioned for light microscopy. MTD was visualized using rabbit anti-MTD serum and silver enhanced colloidal gold. (A) Mannitol-grown and (B) sucrose-grown cells challenged with antiMTD serum. (C) Mannitol-grown cells challenged with preimmune serum. Bars = $50 \mu \mathrm{m}$ (from Zamski et al., 1996; used with permission). 
little reaction when challenged with preimmune serum, illustrating the specificity of the immune reaction (Fig. 1C). Several studies from our laboratory suggest that the lower activity of MTD in cultures grown on sugar is due to repression of Mtd expression by internal glucose and fructose (see Prata et al., 1997; Stoop et al., 1996b). Celery cells growing on sucrose rapidly hydrolyzed sucrose within the growth medium to glucose and fructose, and the cells contained substantial hexose pools but no mannitol (Stoop and Pharr, 1993). Conversely, mannitol-grown cells, which express high MTD activity, contained a very low concentration of sucrose or hexose sugars but a substantial pool of mannitol (Prata et al., 1997; Stoop and Pharr, 1993). Activity of MTD is strongly repressed in cultured celery cells growing on glucose, and is dramatically derepressed upon glucose starvation (Fig. 2). Cultures were initiated at the same cell densities in media with either 90 or $180 \mathrm{~mm}$ glucose. Glucose was low or exhausted from the $90-\mathrm{mm}$ cultures by day 7 or 8 of subculture, whereas 11 or $12 \mathrm{~d}$ were required for glucose depletion in the cultures initiated on $180 \mathrm{~mm}$ (Fig. 2A). While glucose was present, MTD activity in the cells was strongly down-regulated (Fig. 2B). Derepression of MTD activity, temporally correlated with glucose starvation, was observed under both culture conditions. Further, addition of glucose to starving cultures rapidly reduced Mtd RNA, MTD activity, and MTD protein (Prata et al., 1997). When the MTD activity of each cell sample from the experiment in Fig. 2 was plotted against the internal hexose (glucose + fructose) concentration in the cells (Fig. 3), total absence of internal hexoses was not essential for MTD derepression, but highest activities were found in cells with hexose concentrations $<1 \mathrm{mg} \cdot \mathrm{g}^{-1}$ fresh weight.

\section{HEXOKINASE MEDIATES SUGAR REPRESSION OF MTD IN CELERY}

Sugar repression of gene expression, also known as catabolite repression, has been recognized for many years in yeast. When glucose is present, expression of genes involved in utilization of many alternate carbon sources is repressed. Strong evidence suggests that the sugar phosphorylating enzyme HK is the sensor molecule that mediates gene repression. In yeast, Saccharomyces cerevisiae, there are two different HKs, PI and PII, encoded by the genes $H X K 1$ and $H X K 2$, respectively. Either HK isoenzyme is capable of mediating sugar repression of genes (Ronne, 1995; Rose et al., 1991). However, the PII isoenzyme is the major HK involved, because $H K X 1$ itself is repressed by sugar (Ronne, 1995). Both PI and PII are phosphoproteins (Vorjtek and Fraenkel, 1990); PII is autophosphorylated in the presence of ATP (Fernandez et al., 1986), and its protein kinase activity is regulated by glucose concentration (Herrero et al., 1989). Autophosphorylation of PII may initiate a protein phosphorylation cascade that ultimately regulates the activity of transcriptional complexes and hence gene expression (Jang and Sheen, 1997; Koch, 1997). Many genes in plants are known to be regulated by sugars (see review by Koch, 1996). These include genes that are up-regulated ("feast genes") and down-regulated ("fast genes"). Among these are genes encoding invertases and sucrose synthases, both of which are feast genes concerned directly with the catabolic use of translocated sucrose in plant sink tissues.

Transgenic studies with Arabidopsis and other studies with transient gene expression in protoplasts strongly support the idea that $\mathrm{HK}$ serves as the global sensor in mediating sugar repression of plant genes (Jang and Sheen, 1997). Two HK genes were cloned from Arabidopsis and subsequently introduced into transgenic plants in sense and antisense orientations to overexpress or down-regulate $\mathrm{HK}$ in Arabidopsis (Jang and Sheen, 1997). Transformation of Arabidopsis with either sense or antisense constructs of either HK gene had dramatic effects on both HK activity and sensitivity to sugar. Several sugar-regulated responses were measured, including hypocotyl elongation, cotyledon greening, and abundance of $\mathrm{Cab}$ transcripts. Overexpressors of $\mathrm{HK}$ were hypersensitive to sugar repression, whereas antisense, down-regulated phenotypes were hyposensitive to sugar repression relative to wild-type plants.

Additional evidence for the role of $\mathrm{HK}$ as the sugar sensor comes from studies of the effects of glucose analogs and HK inhibitors on plant gene repression [for review, see Jang and Sheen (1997)]. The glucose analog 3-O-methyl glucose is readily taken up by plant cells but is not a substrate or inhibitor of HK. It does not influence the expression of sugar-regulated genes in plants, suggesting that sugar repression is not triggered by glucose uptake. Mannoheptulose, which is a competitive inhibitor of $\mathrm{HK}$ with respect to glucose binding, is not phosphorylated by the enzyme and apparently brings about derepression of sugar-repressed genes by simply limiting access of glucose to the HK catalytic site. The glucose analog 2-deoxyglucose, which is phosphorylated by HK but not further metabolized, mimics glucose in bringing about gene repression. This suggests that subsequent metabolism of the phosphorylated hexose is not required for gene repression.

Use of these inhibitors tentatively establishes that the minimum requirement to initiate the sugar repression signal through plant $\mathrm{HK}$ is the catalytic binding and subsequent phosphorylation of the hexose. The sugar repression/derepression phenomenon is not strictly an on/ off event, but rather a controlled response where the extent of derepression is proportional to sugar concentration within a low concentration range. This is implied from the data in Fig. 3 as well as data published elsewhere (Herbers et al., 1996).

Celery suspension culture is a useful system for studying sugar repression because of the relative ease with which carbon sources and analogs can be manipulated. Data from studies using these cultures (Prata et al., 1997) support the hypothesis that hexose repression of MTD expression is mediated through the hexose phosphorylating

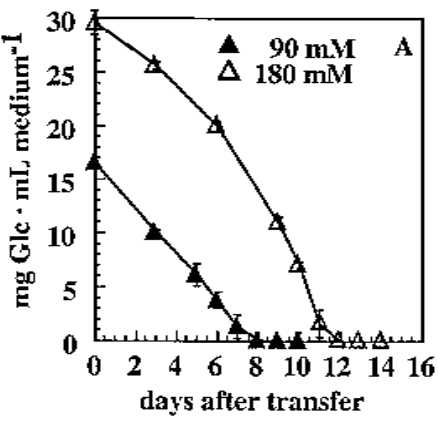

Fig. 2. Relationship between media carbohydrate depletion and derepression of MTD activity in celery suspension cultures growing on either 90 or $180 \mathrm{~mm}$ glucose as the carbon source. (A) Media glucose concentration. (B) MTD enzyme activity. Data are means of three replicates and vertical bars represent \pm standard error (from Prata et al., 1997; used with permission).

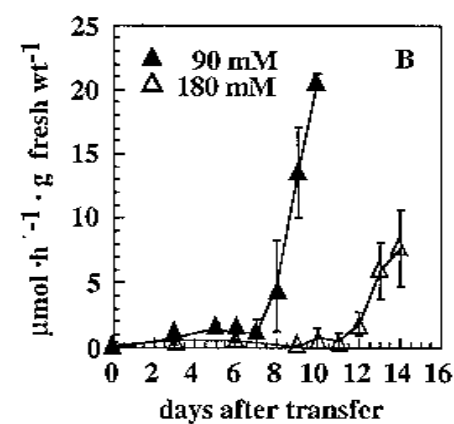

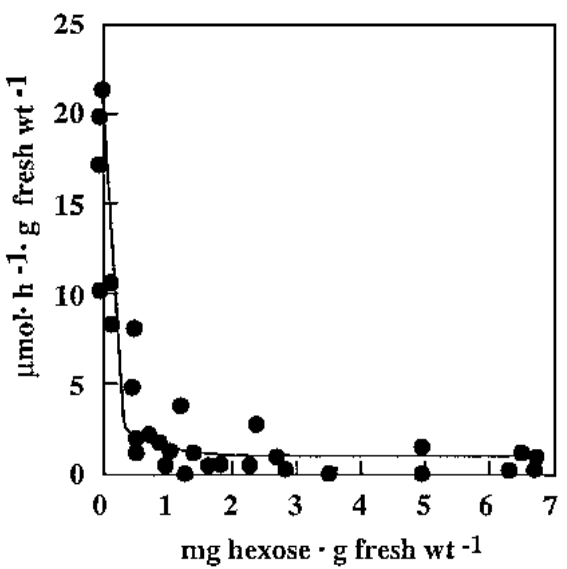

Fig. 3. Relationship between internal hexose (glucose + fructose) concentration and MTD activity for all cell samples from the culture glucose depletion experiment summarized in Fig. 2 (from Prata et al., 1997; used with permission). 

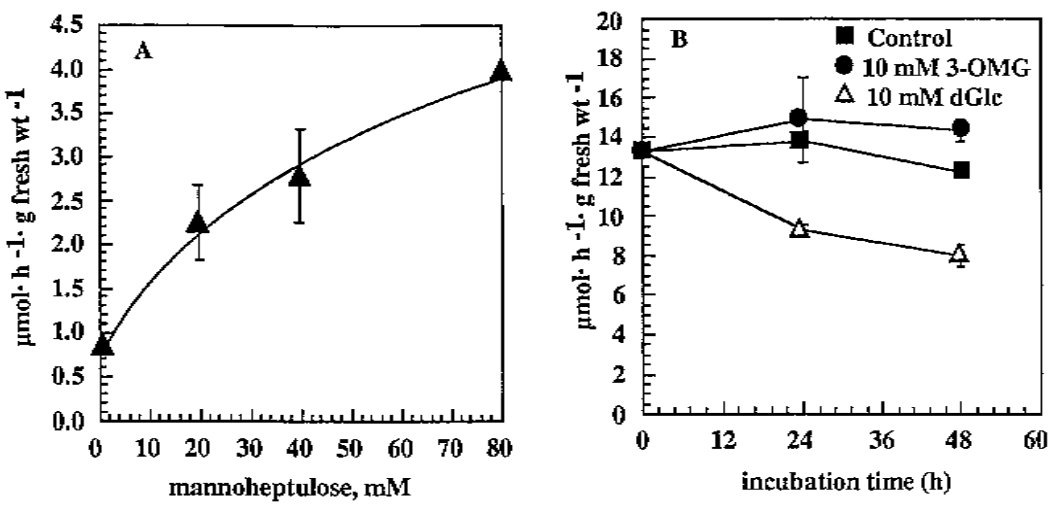

Fig 4. Effects of mannoheptulose and glucose analogs on derepression and repression of MTD activity in celery suspension cultures. (A) Effect of increasing mannoheptulose concentration on MTD activity of celery suspension culture cells growing on glucose. (B) Effect of 3-Omethylglucose and 2-deoxyglucose on MTD activity of celery suspension culture cells growing on mannitol. Cultures were amended with mannoheptulose or glucose analogs $7 \mathrm{~d}$ after subculture and sampled $24 \mathrm{~h}$ later. Data are means of three replicates and vertical bars are \pm standard error [from Prata et al. (1997); used with permission].

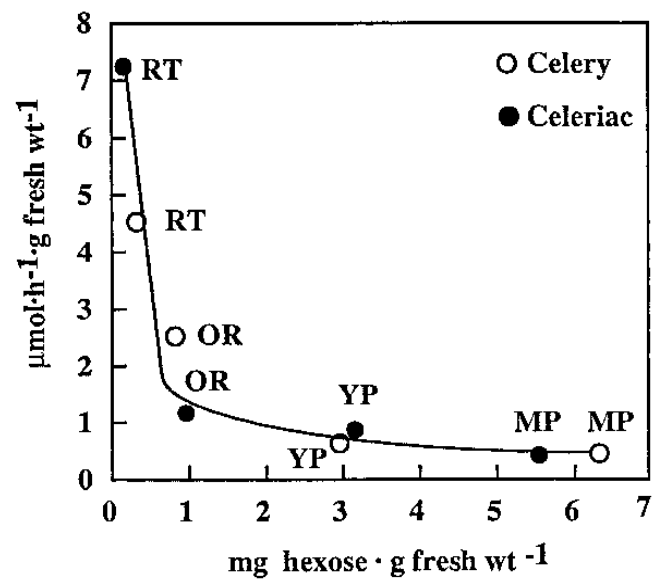

Fig 5. Relationship between internal hexose (glucose + fructose) concentration and MTD activity in different tissues of greenhouse-grown celery and celeriac plants (previously unpublished data of the authors).

enzyme, HK. Regardless of the substrate presented to celery cells, their MTD activity was inversely proportional to the internal concentration of hexoses (glucose + fructose). This was true of celery cells incubated on mannitol, sorbitol, galactitol, glucose, mannose galactose, or fructose. Thus, this array of carbohydrates appears to influence MTD expression to the extent that each is metabolized to sugar substrates of HK. In addition, the effects of the glucose analogs discussed above were precisely as observed in other species with other sugar-repressed plant genes. Mannoheptulose derepressed MTD activity in glucosegrown celery cells in a dose-dependent manner (Fig. 3A). Further, in mannitol-grown cells, 3-O-methyl glucose had no effect, and 2deoxyglucose repressed MTD activity (Fig. 3B). Collectively, these data strongly imply the involvement of HK in mediating sugar repression of MTD in celery suspension-cultured cells.

\section{WHAT IS THE ROLE OF SUGAR REPRESSION OF MTD IN INTACT CELERY PLANTS?}

At present one can only speculate that sugar repression plays important roles in regulating mannitol metabolism in plants, although several observations suggest the critical importance of this phenomenon. Data presented in Fig. 5 from greenhouse-grown celeriac and celery support a hypothesis that sugar concentration is a controlling factor in the tissue-specific distribution of MTD. The activity of MTD in different parts of greenhouse-grown celery and celeriac is plotted as a function of the hexose concentration in the tissue. The similarity in the relationship between tissue hexose concentration and MTD activity in plants (Fig. 5) and in cell cultures (Fig. 3) is striking. This suggests that low tissue hexose concentration may result in derepression of MTD in plants as well as in cell cultures (Figs. 2 and 3). Young, actively growing tissues such as root tips have high carbon demands, resulting in low hexose pools. Speculatively, the low hexose concentration results in MTD derepression and mannitol utilization in these tissues. Such a mechanism would result in conservation of mannitol in all plant parts except those where the total carbon demand cannot be fulfilled by translocated sugar alone.

Alternatively, the relationship in Fig. 5 may only be fortuitous. For instance, mature leaf lamina of celery contains very low hexose pools (not plotted in Fig. 5), yet lacks measurable MTD activity (Stoop and Pharr, 1994). Also, high MTD is evident from immunocytochemical observations in some phloem cells, such as phloem parenchyma, where hexose sugars may be high (Yamamoto et al., 1997). This suggests that factors other than sugar concentration must influence the expression of $M t d$. For instance, salicylic acid (Williamson et al., 1995), phosphate nutrition (Stitt et al., 1995), and perhaps other nutritional factors (Koch, 1997) can modify the response of sugarrepressed genes. Additional, as yet unknown, factors also may be involved in regulating the tissue-specific expression of MTD. Yet, the similarity in correlation between hexose sugar concentration and MTD activity in both cell culture and many tissues of intact plants is compelling evidence that sugar repression of MTD is important. In some plants, sugars accumulate under salt stress. Note that this is not true in celery (Stoop and Pharr, 1994). The strong down-regulation of MTD in salinity-stressed celery is not, at least initially, a response to sugar accumulation in these plants.

Two other observations with celery imply a probable in vivo role of sugar repression of $M t d$. Mannitol functions as a stored carbon and energy reserve in celery. In plants transferred to continuous darkness, sugars are used before mannitol (Fellman and Loescher, 1987). While only speculative, this phenomenon might represent depression of Mtd expression, providing access to the stored mannitol reserves as sugars are depleted. Celery is a biennial plant and accumulates a substantial storage pool of mannitol in its fleshy leaf petioles prior to flowering. This "stored" mannitol is used during flowering in celery only after sugars have been largely depleted (Obaton, 1929). Thus, sugar repression of MTD may function as a major factor determining the use of mannitol temporally as well as spatially in the plant. This mechanism of conservation of photoassimilate allows the plant to accumulate mannitol for use as an osmoprotectant, but also allows the plant to utilize this high-energy carbon reserve under energy-limited conditions.

As more is learned about the complex control of mannitol biosynthesis, phloem- and membrane-transport of mannitol, and mannitol catabolism, it might become possible to engineer plants with the advantageous agricultural characteristics associated with mannitol metabolism. The cloning and study of regulatory elements controlling expression of the genes involved in the mannitol metabolic pathway will be of critical importance in successfully engineering plants with appropriate regulation.

\section{Authors' Addendum:}

Subsequent to acceptance of this article for publication, two important discoveries occurred that are important to the discussion. L-galactose was discovered to be an important intermediate in the biosynthesis of L-ascorbic acid by plants, and the gene product of ELI3 was shown to oxidize D-mannitol.

\section{Literature Cited}

Durner, J., J. Shah, and D.F. Klessig. 1997. Salicylic acid and disease resistance in plants. Trends Plant Sci. 2:266-274.

Everard, J.D., V.R. Franceschi, and W.H. Loescher. 1993. Mannose-6-phosphate reductase, a key enzyme in photoassimilate partitioning, is abundant and located in the cytosol of photosynthetically active cells of celery 
(Apium graveolens L.) source leaves. Plant Physiol. 102:345-356.

Fellman, J.K. and W.H. Loescher. 1987. Comparative studies of sucrose and mannitol utilization in celery (Apium graveolens). Physiol. Plant. 69:337341.

Fernandez, R., P. Herrero, M.T. Fernandez, and F. Moreno. 1986. Mechanism of inactivation of hexokinase PII of Saccharomyces cerevisiae by Dxylose. J. Gen. Microbiol. 132:3467-3472.

Flora, L.L. and M.A. Madore. 1993. Stachyose and mannitol transport in olive (Olea europaea L.). Planta 189:484-490.

Herbers, K., P. Meuwly, W.B. Frommer, J. Metraux, and U. Sonnewald. 1996. Systemic acquired resistance mediated by the ectopic expression of invertase: Possible hexose sensing in the secretory pathway. Plant Cell 8:793-803.

Herrero, P., R. Fernandez, and F. Moreno. 1989. The hexokinase isoenzyme PII of Saccharomyces cerevisiae is a protein kinase. J. Gen. Microbiol. 135:1209-1216.

Jang, J. and J. Sheen. 1997. Sugar sensing in higher plants. Trends Plant Sci. 2:208-214.

Karakas, B., P. Ozias-Akins, C. Stushnoff, M. Suefferheld, and M. Rieger. 1997. Salinity and drought tolerance of mannitol-accumulating transgenic tobacco. Plant Cell Environ. 20:609-616.

Koch, K.E. 1996. Carbohydrate-modulated gene expression in plants. Annu. Rev. Plant Physiol. Plant Mol. Biol. 47:509-540.

Koch, K.E. 1997. Molecular crosstalk and the regulation of C- and Nresponsive genes, p. 105-124. In: C. Foyer and P. Quick (eds.). A molecular approach to primary metabolism in plants. Taylor and Francis, London.

Le Rudulier, D., A.R. Strom, A.M. Dandekar, L.T. Smith, and R.C. Valentine. 1984. Molecular biology of osmoregulation. Science 224:1064-1068.

Loescher, W.H., R.H. Tyson, J.D. Everard, R.J. Redgwell, and R.L. Bieleski. 1992. Mannitol synthesis in higher plants. Plant Physiol. 98:1396-1402.

Moore, B., D.E. Palmquist, and J.R. Seemann. 1997. Influence of plant growth at high $\mathrm{CO}_{2}$ on leaf content of ribulose-1,5-bisphosphate carboxylase/ oxygenase and intracellular distribution of soluble carbohydrates in tobacco, snapdragon, and parsley. Plant Physiol. 115:241-248.

Nolte, K.D. and K.E. Koch. 1993. Companion-cell specific localization of sucrose synthase in zones of phloem loading and unloading. Plant Physiol. 101:899-905.

Obaton, M.F. 1929. Evolution de la mannite chez les végétaux. Rev. Gen. Bot. 41:622-633.

Pharr, D.M., J.M.H. Stoop, M.E. Studer-Feusi, J.D. Williamson, M.O. Massel, and M.A. Conkling. 1995. Mannitol catabolism in plant sink tissues, p. 180-194. In: M.A. Madora and W.J. Lucas (eds.). Current topics in plant physiology. vol. 13. Carbon partitioning and source-sink interactions in plants. Amer. Soc. Plant Physiol.

Pharr, D.M., J.M.H. Stoop, J.D. Williamson, M.E. Studer Feusi, M.O. Massel, and M.A. Conkling. 1995. The dual role of mannitol as osmoprotectant and photoassimilate in celery. HortScience 30:1182-1188.

Prata, R.T.N., J.D. Williamson, M.A. Conkling, and D.M. Pharr. 1997. Sugar repression of mannitol dehydrogenase activity in celery cells. Plant Physiol. 114:307-314.

Ronne, H. 1995. Glucose repression in fungi. Trends Genet. 11:12-17.

Rose, M., W. Albir, and K.D. Entian. 1991. Glucose repression in Saccharomyces cerevisiae is directly associated with hexose phosphorylation by hexokinases PI and PII. Eur. J. Biochem. 199:511-518.
Rumpho, M.E., G.E. Edwards, and W.H. Loescher. 1983. A pathway for photosynthetic carbon flow to mannitol in celery leaves. Activity and localization of key enzymes. Plant Physiol. 73:869-873.

Shen, B., R.G. Jensen, and H.J. Bohnert. 1997. Increased resistance to oxidative stress in transgenic plants by targeting mannitol biosynthesis to chloroplasts. Plant Physiol. 113:1177-1183.

Smirnoff, N. 1993. Tansley review no. 52: The role of active oxygen in the response of plants to water deficit and desiccation. New Phytol. 125:27-58.

Smirnoff, N. and Q.J. Cumbes. 1989. Hydroxyl radical scavenging activity of compatible solutes. Phytochemistry 28:1057-1060.

Stitt, M., A. Krapp, D. Klein, U. Roper-Schwarz, and M. Paul. 1995. Do carbohydrates regulate photosynthesis and allocation by altering gene expression?, p. 68-77. In: M.A. Madora and W.J. Lucas (eds.). Current topics in plant physiology: Vol. 13. Carbon partitioning and source-sink interactions in plants. Amer Soc. Plant Physiol.

Stoop, J.M.H., W.S. Chilton, and D.M. Pharr. 1996a. Substrate stereospecificity of the NAD-dependent mannitol dehydrogenase from celery. Phytochemistry 43:1145-1150.

Stoop, J.M.H. and D.M. Pharr. 1992. Partial purification and characterization of mannitol: mannose 1-oxidoreductase from celeriac (Apium graveolens var. rapaceum) roots. Arch. Biochem. Biophys. 298:612-619.

Stoop, J.M.H. and D.M. Pharr 1993. Effect of different carbon sources on relative growth rate, internal carbohydrates, and mannitol 1-oxidoreductase activity in celery suspension cultures. Plant Physiol. 103:1001-1008.

Stoop, J.M.H. and D.M. Pharr 1994. Growth substrate and nutrient salt environment alter mannitol to hexose partitioning in celery petioles. J. Amer. Soc. Hort. Sci. 119:237-242.

Stoop, J.M.H., J.D. Williamson, M.A. Conkling, and D.M. Pharr. 1995. Purification of NAD-dependent mannitol dehydrogenase from celery suspension cultures. Plant Physiol. 108:1219-1225.

Stoop, J.M.H., J.D. Williamson, and D.M. Pharr. 1996b. Mannitol metabolism in plants: a method for coping with stress. Trends Plant Sci. 1:139-144.

Tarczynski, M.C., R.G. Jensen, and H.J. Bohnert. 1992. Expression of a bacterial $m t l D$ gene in transgenic tobacco leads to production and accumulation of mannitol. Proc. Natl. Acad. Sci. 89:2600-2604.

Tarczynski, M.C., R.G. Jensen, and H.J. Bohnert. 1993. Salt protection of transgenic tobacco by production of the osmolyte mannitol. Science 259:508-510.

Thomas, J.C., M. Sepahi, B. Arendall, and H.J. Bohnert. 1995. Enhancement of seed germination in high salinity by engineering mannitol expression in Arabidopsis thaliana. Plant Cell Environ. 18:801-806.

Vojtek, A.B. and D.G. Fraenkel. 1990. Phosphorylation of yeast hexokinases. Eur. J. Biochem. 190:371-375.

Williamson, J.D., J.M.H. Stoop, M.O. Massel, M.A. Conkling, and D.M. Pharr. 1995. Sequence analysis of a mannitol dehydrogenase cDNA from plants reveals a function for the pathogenesis-related protein ELI3. Proc. Natl. Acad. Sci. 92:7148-7152.

Yamamoto, Y.T., E. Zamski, J.D. Williamson, M.A. Conkling, and D.M.Pharr. 1997. Subcellular localization of celery mannitol dehydrogenase: A cytosolic metabolic enzyme in nuclei. Plant Physiol. 115:1397-1403.

Zamski, E., Y.T. Yamamoto, J.D. Williamson, M.A. Conkling, and D.M. Pharr. 1996. Immunolocalization of mannitol dehydrogenase in celery plants and cells. Plant Physiol. 112:931-938. 